UDC 581.143.6+634.723.1

(C) 2016

T. Medvedeva, Candidate of Biological Sciences

N. Triapitsyna, T. Natalchuk, Candidates of Agricultural Sciences

Ya. Zapolskyi

Institute of Horticulture of NAAS

\title{
MICROCLONAL PROPAGATION BLACK CURRANT
}

The purpose. To optimize separate stages of microclonal propagation black currant and to develop complex techniques of the sped up propagation for new cultivars on the basis of biotechnological methods. Methods. Preparation of nutrient mediums, and cultivation of plants in vitro was made under practical standards.

Results. Specific features of deriving aseptic crop black currant of cultivar Saniuta and elite form 01 - 1 - 9 are probed. Nutrient mediums for proliferation and rootage in crop in vitro and methods of acclimatization to conditions ex vitro are selected. Positive influence of Acidum ascorbinicum upon efficiency of cultivation of microscions is shown. Conclusions. For deriving aseptic crop black currant as explants the most suitable are apical and lateral buds got from green scions. Addition of Acidum ascorbinicum $(0,57 \mathrm{mM})$ into medium for initiation of aseptic crop and proliferation prevents depression of recovery and growth activity of explants which is caused by oxidation of phenols. Adaptation on substrate «Domoflor mix 3» ensures neogenesis 91 - 98\% of microscions.

Key words: European black currant, aseptic crop, explant, in vitro.

Black currant (Ribes nigrum L.) is characterized by high yield, early ripening and high berries quality. They, in turn, distinguish themselves for medical properties. For example, as to the vitamin $\mathrm{C}$ contain although they are somewhat inferior to the dog rose berries, but exceed those of strawberry by 5 times, raspberry and gooseberry by 7-8 times, and in combination with vitamin $\mathrm{P}$ are irreplaceable in the treatment of cardiovascular diseases and under excessive irradiation doses [8].

Recently state programs directed to increasing the fruit and berries gross production volumes are adopted in Ukraine. The other emerging trend is to increase the manufacturing of black currant berries. That demands the improvement the existing assortment, introduction varieties which are resistant to diseases, pests and adverse 
environmental conditions and use of intensive technologies, achievements in science. Engine ering and advanced practices.

The important alternative in phytovirusological control and preservation of genetic resources is the in vitro culture and plants microclonal propagation. In combination with thermos-or chemotherapy, this method enables the sanitation of valuable cultivars or forms that exist in limited quantities.

We know a number of papers on the black currant microclonal reproduction [3, 4, 10, 11]. But taking into consideration that the regenerative ability of this crop isolated tissues depends on the parental plants specificity, nutritive medium composition and growth regulators concentration, the optimization of individual stages for specific genotypes and development of comprehensive technologies for the accelerated propagation of new varieties on the basis of biotechnological methods remains actual.

Materials and methods. The researches was conducted in the Department of Virology, Sanitation and Propagation of Fruits and Small Fruits of the Institute of Horticulture NAAS during 2014-2015 using the black currant varietiesSanyuta, Galaktyka, Debut and elite forms 01-1-9 and 99-20-16 of the IH breeding. Shoots with buds in the dormancy state were cut in January-March and germinated under the controlled conditions before removing explants for the introduction into the in vitro culture. Hardwood shoots were selected in August. Apical and axillary buds were used as explants when initiating the aseptic culture and the $0,1 \%$ solution $\mathrm{HgCl}_{2}$ adding the $70 \%$ ethanol and commercial bleach diluted at a ratio of $1: 5$ as a sterilizing agent. The preparation of media and in vitro plants cultivation were carried out according to conventional methods [2]. At stage of the introduction into the culture and proliferation the Murashige-Skoog (MS) medium were usedwith different modification.

The measures aimed at adaptation the rooted shoots that had achieved a size of $2 \mathrm{~cm}$ or more to the ex vitro conditions were conducted from the early April in a 
greenhouse in the peat substrate "Domoflor mix3" (Lithuania) with the addition of a small amount of perlite.

Results.Obtaining the sterile culture is the first and the very important stage under the microclonal propagation, especially for the small fruits because their long vegetative propagation as a rule causes mass contamination of stands with pathogenic microflora that inhibits the explants development in the nutrient medium. Apical and axillary buds from soft -and hardwood shoots were sterilized with the $0,1 \%$ mercury chloride solution as the most effective sterilant for black currantaccording to the literature data [3]. The sterilization exposure lasted 4 or 5 minutes. The highest yield of the aseptic material (69\%) was achieved of EF 01-19from the buds that had been isolated out of soft shoots (table. 1). The hard-wood ones proved not very good sources of explants because of the high background of epiphytic microflora. In general the yield of sterile explants was the not high under the both sterilization regimes. In addition, in the process of the further cultivation appeared latent infection, which resulted in the loss of the regenerants of cvsGalaktyka, Debut and elite form 99-20-16. So we used the cultivar Sanyuta and form 01-1-9 at the next stages of the technological link of the microclonal introducing black currant plants into the in vitro culture occur in the works of other authors [9].

We consider that the pretreatment of the explants source with a complex of pesticides and maintenance of the initial material under controlled conditions can reduce significantly the contamination level. Besides, in order to obtain more aseptic explants the sterilization exposure should be increased. The treatment explants with the $0,1 \% \mathrm{HgCl}_{2}$ solution for 15 minutes did appear to increase sterilization effectiveness from 70 to $100 \%$ [3].

1. Effect of the sterilization regime and of the black currant explants type on the effectiveness of the introduction into the in vitro culture

\begin{tabular}{|l|l|ll|l|}
\hline \multirow{4}{*}{ Eultivar } & \multicolumn{3}{|c|}{ Sterile explants yield, \% } \\
\cline { 2 - 5 } & $\mathrm{HgCl}_{2}$ 0,1\%, 4 minutes & $\mathrm{HgCl}_{2}$ 0,1\%, 5 minutes \\
\cline { 2 - 5 } & Soft shoots & Hard-wood & Soft shoots & Hard-wood \\
\hline
\end{tabular}




\begin{tabular}{|l|c|c|c|c|}
\hline & & shoots & & shoots \\
\hline Galaktyka & 45 & 28 & 49 & 31 \\
\hline Debut & 39 & 23 & 43 & 27 \\
\hline Sanyuta & 51 & 26 & 57 & 33 \\
\hline $01-1-9$ & 63 & 31 & 69 & 35 \\
\hline $99-20-16$ & 37 & 24 & 41 & 29 \\
\hline
\end{tabular}

For the regeneration of micro shoots the explants were inoculated on the MS medium which contained $0,5 \mathrm{mg} / \mathrm{l} \mathrm{BAP}$ - cytokinin, which is the most often used to stimulate the shoots formation [10]. Indole butyric and gibberellic acids $(0,1 \mathrm{mg} / \mathrm{l}$ of each) were added. The isolated bud survival rate was calculated every 30 days of the cultivation (table.2).

2. Black currant explants survival rate after the introduction into the in vitro culture

\begin{tabular}{|l|c|c|c|c|}
\hline \multirow{2}{*}{} & \multicolumn{4}{|c|}{ Explants survival rate, \% } \\
\cline { 2 - 5 } & \multicolumn{3}{|c|}{ Buds from the soft shoots } & \multicolumn{2}{c|}{$\begin{array}{c}\text { Buds from the hard-wood } \\
\text { shoots }\end{array}$} \\
\cline { 2 - 5 } Fenotype & apical & lateral & apical & lateral \\
\hline Sanyuta & 73 & 81 & 62 & 53 \\
\hline p1-1-9 & 86 & 93 & 67 & 61 \\
\hline
\end{tabular}

In the both genotypes studied the higher percentage of surviving shoots was observed among the lateral buds isolated from the soft shoots and apical buds from the hard-wood shoots. The explants EF 01-1-9 surviving was somewhat higher than that of the cultivar Sanyuta. In general both the apical and lateral buds can serve as a reliable source of explants when initiating the aseptic culture of black currant. Our results do not contradict the data in other researches (e.g.cvs Golubka and Altayskaya dyesyertnaya) [7].

The micro shoots that developed from the isolated explants during the first month of cultivation were transplanted to the medium for the formation of rosettes (Fig.1.). 


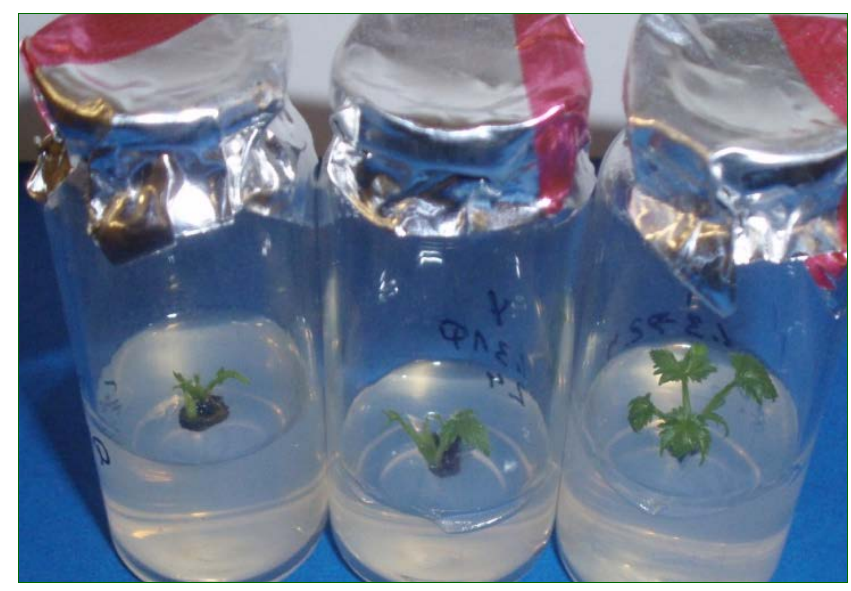

Fig.1. Regeneration from the black currant primary explants the cultivar Sanyuta in the in vitro culture

The micro plants regeneration from primary explants and black currant proliferation are often accompanied with the exudation of the phenols oxidative products into the nutrient medium, which inhibit regeneration and growth processes. In order to reduce the activity of oxidative enzymes, antioxidants are used such as ascorbic and citric acids, glutathione, polyvinyl ditiotryetol and others [1]. We managed to obtain healthy explants by adding the ascorbic acid at a concentration of $0,57 \mathrm{mM}$ to the medium at the first and further cultivation stages. Reducing the passage duration up to 30 days also decreases the negative effects associated with the oxidation of phenols and contributes to the intensive growth micro shoots. According to published data, the long cultivation of the micro shoots on the medium reduces the growth activity by $11-20 \%$ [5].

To stimulate the development of adventitious shoots BAP in concentrations of 0,5; 0,8 and $1,0 \mathrm{mg} / \mathrm{l}$ was added to the nutrient medium. The indole butyric acid content remained constant in all the variants. The shoot formation coefficient and micro shoots length were determined (table.3).

The first of this indicators rose when the BAP concentration increasing but the decrease of the micro shoots height in the rosettes was observed with the dominance of one or two high. To elongate the micro shoots the gibberellic acid (GA) concentration in the cultivation medium was raised by $1,0 \mathrm{mg} / \mathrm{l}$. The micro shoots high increasing inconsiderably and individual plants that were higher became lignified and their ability to be reproduced decreased. The GA concentration of 0,5 
$\mathrm{mg} / \mathrm{l}$ proved optimum at the multiplication stage and that of $0,1 \mathrm{mg} / \mathrm{l}$ at the rooting stage.

3. BAP concentration effect on the black currant proliferation

\begin{tabular}{|l|c|c|c|}
\hline Genotype & BAP content, mg/l & $\begin{array}{c}\text { Propagation } \\
\text { coefficient }\end{array}$ & $\begin{array}{c}\text { Average shoot } \\
\text { length, mm }\end{array}$ \\
\hline \multirow{3}{*}{ Sanyuta } & 0,5 & $2,5 \pm 0,37$ & $11,3 \pm 1,53$ \\
\cline { 2 - 4 } & 0,8 & $3,2 \pm 0,19$ & $19,5 \pm 2,21$ \\
\cline { 2 - 4 } & 1,0 & $3,5 \pm 0,25$ & $14,7 \pm 1,64$ \\
\hline \multirow{2}{*}{ EF 01-1-9 } & 0,5 & $2,8 \pm 0,29$ & $13,4 \pm 1,59$ \\
\cline { 2 - 4 } & 0,8 & $3,4 \pm 0,34$ & $18,7 \pm 2,54$ \\
\cline { 2 - 4 } & 1,0 & $3,6 \pm 0,26$ & $16,5 \pm 2,05$ \\
\hline
\end{tabular}

When cultivating the researched crop leaf chlorosis was often observed that have noted other researchers as well [11]. The addition of the iron chelate double concentration removed this negative phenomenon.

The multi shoots formation was influenced favorably by the replacement sucrose for glucose or use of the two carbohydrates in equal amounts. In the horizontally oriented shoots a higher propagation coefficient could be achieved than on the oriented vertically ones. The increase of this index was contributed by planting micro shoots on the medium not as single plants but also as small clusters.

The micro plants rooting was stimulated in the medium which contain the rhizogenesis inductor (IBA) at a concentration of $0,1 \mathrm{mg} / \mathrm{l}$, while sucrose of $20 \mathrm{~g} / \mathrm{l}$. The rooting lasted 20-30 days.

Black currant plants root easily enough on the medium without plant growth regulators too when the micro shoots height is $2 \mathrm{~cm}$ and more. In the both genotypes the percentage of the rooted plants was 95-100. The plants with a good root systems were planted into the adaptation cassettes (fig.2).

The adaptation, as well as initiation of aseptic culture, although for different reasons, but is the main problem of all the microclonal propagation technologies. The plant grown under in vitro conditions have poorly developed leading xylem 
system and stoma apparatus. The regenerants surviving in non-sterile conditions, first of all depends on their ability to withstand low humidity. As leaf blades are deprived of the epicuticular wax they dehydrate themselves quickly when being removed from the in vitro to the ex vitro conditions and are lost [6]. So, the choice of the adaptation conditions is especially important. Much attention being paid to the substrate quality which must be easy for good roots aeration, nutritive and retain moisture. It is the substrate "Domoflor mix 3" (Lithuania), that meets these requirements.

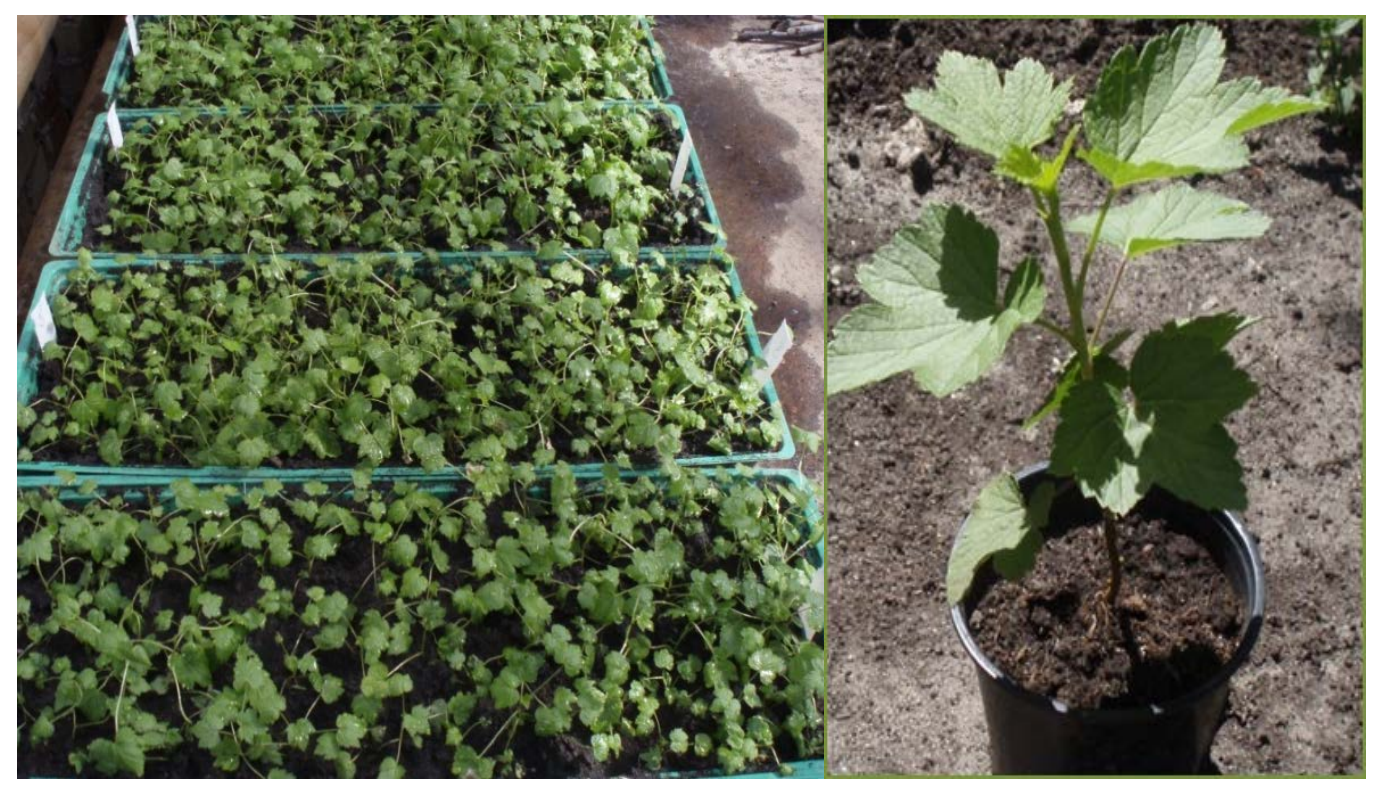

Fig.2. Adaptation of the black currant plants to the ex vitro conditions The adaptation of the rooted shoots that had reached $2 \mathrm{~cm}$ and more to the ex vitro conditions was carried out from the beginning of April. In order to maintain the high humidity level (90-100\%) trays with the planted micro shoots were covered with plastic wrap, which were uncovered gradually and fully removed on the seventhtenth day. The temperature in the greenhouse at the beginning of the adaptation was supported within $15-18^{\circ} \mathrm{C}$. Under such conditions the adapted plants yield was 91$98 \%$.

\section{Conclusions.}

1. For the black currant aseptic culture initiation apical and lateral buds are the most suitable as explants if they are isolated from soft shoots. 
2. The addition of the ascorbic acid at a concentration of $0,57 \mathrm{mM}$ into the medium for the aseptic culture initiation and proliferation prevents explants browning and regenerative activity reducing caused by the phenols oxidation.

3. For the black currant cultivation the medium Murashige-Skoog is optimal containing 0,8-1,0 mg/l BAP, 0,5 mg/l GA and the double concentration of iron chelate.

4. The studied genotypes are rooted for 20-30 days in the medium that contains 0,1 $\mathrm{mg} / \mathrm{l}$ of IBA/ The rooting is $95-100 \%$.

5. The adaptation on the substrate "Domoflor mix 3"provides the regeneration of 91985 micro plants.

\section{Bibliography}

1. Silenko V.O. Suitability of currant varieties (Ribesnigrum L.) of NUBiP Ukraine selection for mechanized picking of berries/VA. Silenko, P.M. Hawaii//Graduate study and protection of rights to plant varieties. - 2013. - No. 3. - P. 13 - 17.

2. Klyuddenko A.A. Features of obtaining aseptic culture Ribes nigrum L.A.A. Klyuddenko, S.Yu. Bilous, O.V. Overchko//Scientific. add NUBIP - 2014 - 9 p.

3. Kolbanova E.V. Micropropagation method of black currant in vitro/E.V. Kolbanova, N.V. Kukharchik//Fruit growing: Sat. scientific Art./Institute of Fruit Production of the National Academy of Sciences of Belarus. - Samokhvalichy, 2006. - T. 2. - Ch. 2. - P. 163 - 168.

4. In vitro propagation of black currant 'PerlaNeagra' and 'Amurg' cultivars/D. Clapa, A. Fira, C Plop, A. Bergs//Scientific papers of the RIFGPiteshti. - 2009. - V. XXV. - P. 207 - 212.

5. Repeat D. Micropropagation as a means of rapid multiplication of newly-developed blackberry and black currant cultivars/D. Ruźić, T. Lazić//Agriculturae Conspectus Bibliography Scientificus. - 2006. - V. 71. - No. 4. - P. 149 - 153.

6. Butenko R.G. The culture of isolated tissues and physiology of plant morphogenesis/R.G. Butenko - M., 1964. - 272 p. 
7. Skovorodnikov D.N. Clonal micropropagation in accelerating the selection process of currant black//Scientific paper. Vedic Series Natural Sciences. - 2012. - No. 21 (140). - P. 58 - 61.

8. Clonal reproduction of plants of black currant (Ribesnigrum L.) in vitro/GK. Orazbaeva V.T. Khasanov, AR Iskakov, V.K. Shvidchenko//Vestn. science KazatU them. S. Seyfullin. - 2012. - No. 1 (72). - P. 245 - 257.

9. Matushkina O.V. Features of currant multiplication in vitro/O.V. Matushkina, I.N. Pronina//Modern condition of the culture of currant and gooseberry: Sat. scientific tr - Michurinsk, 2007. - P. 285 - 289.

10. Medvedeva T.V. Problems of acclimatization of cultured in vitro plants/T.V. Medvedev//Physiology and biochemistry of cultivated plants. - 2008. - Vol. 40, No. 4. - P. 299 - 309. 